\title{
COMENTARIOS
}

\section{Notas sobre taxonomía, biología y pesquería de Ucides occidentalis (Brachyura: Ocypodidae) con énfasis en el Golfo de Guayaquil, Ecuador}

\section{Notes on taxonomy, biology and fishery of Ucides occidentalis (Brachyura: Ocypodidae) with emphasis in the Gulf of Guayaquil, Ecuador}

\author{
René Zambrano* ${ }^{*}$ y César Meiners ${ }^{2}$
}

\begin{abstract}
1 Departamento de Ciencias del Mar, Escuela de Biología, Facultad de Ciencias Naturales, Universidad de Guayaquil, Av. Raul Gómez Lince S/N y Av. Juan Tanca Marengo, Guayaquil, Guayas 090601, Ecuador. eddie_zam89@hotmail.com

2 Instituto de Ciencias Marinas y Pesquerías, Universidad Veracruzana, Hidalgo \#617, Colonia Río Jamapa, Boca del Rio, Veracruz 94290 , México.

*Autor para correspondencia

Email René Zambrano: eddie_zam89@hotmail.com

Email César Meiners: cmeiners@uv.mx
\end{abstract}

\section{Resumen}

La información científica sobre Ucides occidentalis es escasa y parte de estos estudios no han logrado una difusión adecuada, lo cual restringe la disponibilidad de conocimiento sobre esta especie comercial. En este trabajo se revisan diversos estudios sobre $U$. occidentalis y se presenta información obtenida de observaciones directas realizadas entre 2011-2014 en los manglares del Golfo de Guayaquil, Ecuador. Se muestran notas sobre cambios en la taxonomía de $U$. occidentalis, sus características biológicas, ecológicas y pesqueras. Se discuten características del interés pesquero como la densidad poblacional y períodos de reproducción. Finalmente, se discute el manejo de las pesquerías de U. occidentalis en el Golfo de Guayaquil debido a que, en los últimos años, se ha evidenciado una disminución en los niveles de desembarques y a la vez, un aumento en la talla media comercial; aquello sugiere que se deben considerar ambos factores en la evaluación del stock, para tener una mejor aproximación sobre el estado poblacional del recurso y sus niveles de explotación.

Palabras claves: Comercialización; crustáceo; ecología; manglar; pesquería.

\begin{abstract}
Scientific information on Ucides occidentalis is scarce, and part of these studies have not adequate diffusion, this situation restricts the availability of knowledge about this commercial species. In this work, on the one hand, diverse studies on $U$. occidentalis are reviewed, and on the other, information obtained from direct observations made since 2011 to 2014 in the Gulf of Guayaquil mangroves, is presented. Notes on changes in the taxonomy of $U$. occidentalis, its biology, ecological and fishery characteristics are presented. Characteristics to fishing interest such as density data and reproduction periods are discussed. By last, it is discussed the management of fisheries of $U$. occidentalis in the Gulf of Guayaquil, because in recent decades, $U$. occidentalis has evidenced a decrease in the landing levels and at the same time, an increase in the average commercial size; this suggest that both factors should be considered in the evaluation of stock, and thereby to have a better approximation on the population status of the resource.
\end{abstract}

Keywords: Commercialization; crustacean; ecology; mangrove; fishery.

Citación:

Zambrano R. \& C. Meiners. 2018. Notas sobre taxonomía, biología y pesquería de Ucides occidentalis (Brachyura: Ocypodidae) con énfasis en el Golfo de Guayaquil, Ecuador. Revista peruana de biología 25(1): 055 - 066 (Febrero 2018). doi: http://dx.doi.org/10.15381/rpb.v25i1.13821

$\begin{array}{ll}\text { Presentado: } & 13 / 09 / 2017 \\ \text { Aceptado: } & 06 / 12 / 2017 \\ \text { Publicado online: } & 27 / 02 / 2018\end{array}$

Información sobre los autores:

RZ, CM: redactaron, revisaron y aprobaron el manuscrito.

Los autores no incurren en conflictos de intereses. 


\section{Introducción}

Las pesquerías de crustáceos tienen gran importancia debido a su valor económico unitario (Smith \& Addison 2003), en particular, en bosques de manglar y zonas adyacentes podemos encontrar varias especies de braquiuros como Cardisoma guanhumi (Latreille 1825), Ucides cordatus (Linnaeus 1763), U. occidentalis (Ortmann 1897), Giopnopsis cruentata (Latreille 1802) y Callinectes spp. (Alves et al. 2005, Magalhães et al. 2012, Solano et al. 2010).

Ucides occidentalis es una especie de interés comercial que habita en los manglares de la costa oeste de América, desde la isla Espíritu Santo (México) hasta el estuario San Pedro en Perú (Alemán \& Ordinola 2017, Bright \& Hogue 1972, Solano et al. 2012). En Ecuador, U. occidentalis se distribuye en la costa continental y es conocido como "cangrejo rojo" o "guariche", además, es el crustáceo artesanalmente explotado de mayor importancia económica (Alava et al. 2015, Cruz et al. 2003, Moreno \& Ruiz 2010, Muñiz \& Peralta 1983, Solano et al. 2010, Zambrano \& Solano 2014).

La antigüedad de la pesquería de $U$. occidentalis en Ecuador es desconocida, pero en 1973 ya era reconocida como una especie tradicionalmente comercial, cuyos pescadores tenían entre 25 y 30 años de experiencia y que era considerada superior a otros cangrejos como Callinectes spp. (Barragán 1993, Oesterling $\&$ Petrocci 1995). La información acerca de U. occidentalis se encuentra contenida primordialmente en reportes científicos y técnicos del Instituto Nacional de Pesca (INP), referida al análisis descriptivo de sus desembarques pesqueros y/o aspectos biológicos específicos en el Golfo de Guayaquil, Ecuador. Ade- más, existe literatura gris (e.g., tesis) que abarca temas como el contenido de metales pesados, procesamiento y comercialización de $U$. occidentalis.

La información científica sobre $U$. occidentalis es escasa y la literatura verde es poco conocida, lo cual influye en la toma de decisiones y en la generación de nuevas investigaciones sobre esta especie. Por ello, el objetivo de este trabajo es integrar el conocimiento acumulado sobre $U$. occidentalis referente a los aspectos taxonómicos y biológicos, además de, las características de la pesquería de este recurso como operatividad, manejo pesquero y desembarques; también, se proporciona información adquirida mediante observaciones directas in situ realizadas en el Golfo de Guayaquil, Ecuador.

\section{Material y métodos}

El Golfo de Guayaquil es el mayor estuario tropical de la costa oeste de Sudamérica (Jiménez 1983) y en esta área se han desarrollado la mayoría de los estudios sobre $U$. occidentalis; principalmente en tres zonas de este golfo: Mondragón, Churute y Naranjal (Fig. 1). La información sobre U. occidentalis se obtuvo de repositorios digitales (e.g., http://repositorio.ug.edu.ec/), revistas científicas y reportes técnicos del Instituto Nacional de Pesca. Los trabajos analizados fueron desarrollados y sintetizados según su orientación temática en diferentes apartados.

\section{Taxonomía de Ucides occidentalis}

El género Ucides (Rathbun 1897) ha sido objeto de varios cambios de familia debido a que, su afinidad filogenética durante varios años ha sido incierta ( $\mathrm{Ng}$ et al. 2008). Inicialmente, Ucides occidentalis constó en la familia Gecarcinidae (MacLeay 1838) por su similitud morfológica con géneros de esa familia como
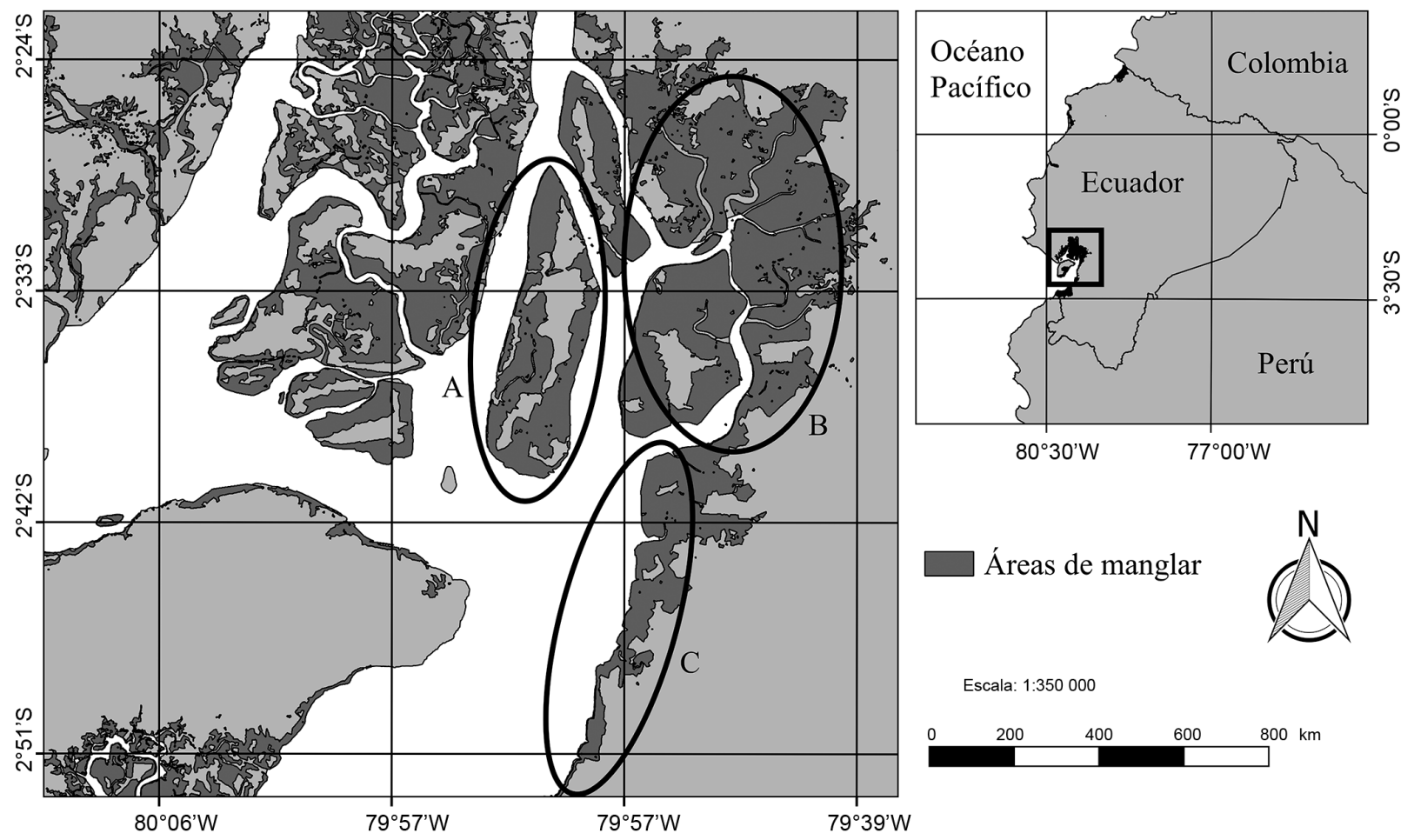

$80^{\circ} 30^{\prime} \mathrm{W} \quad 77^{\circ} 00^{\prime} \mathrm{W}$

Áreas de manglar

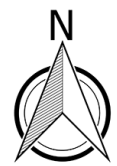

Escala: 1:350 000

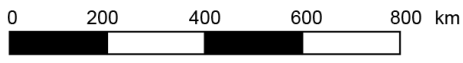

Figura 1. Áreas de manglar donde habita Ucides occidentalis (Ortmann, 1897) en el Golfo de Guayaquil, Ecuador. Principales zonas de observación. a, Mondragón; b, Churute; c, Naranjal. Tomado de Zambrano (2016). 
Cardisoma (Latreille in Latreille, Le Peletier, Serville \& Guérin 1828), (Ng et al. 2008). Chace y Hobbs (1969), en un estudio realizado sobre cangrejos decápodos terrestres, incluyeron el género Ucides dentro de la familia Ocypodidae (Rafinesque 1815). La reclasificación taxonómica de los braquiuros incluyó el género Ucides en la subfamilia Ucidinae, la cual fue elevada a familia (Ucididae) posteriormente (Ng et al. 2008, Števčić 2005). Sin embargo, estudios moleculares y filogenéticos han concluido que, $U$. occidentalis pertenece a la familia Ocypodidae (Schubart \& Cuesta 2010, Shih et al. 2016). La conclusión mencionada se centró en las variaciones taxonómicas de $U$. occidentalis a nivel de familia, pero también se han registrado cambios en su subfamilia, lo cual se puede revisar a profundidad mediante la literatura citada. La escala taxonómica in extenso de U. occidentalis se puede consultar en la página World Register of Marine Species (www.marinespecies.org), pero con fines prácticos se detalla una parte:

$\begin{array}{ll}\text { Reino: } & \text { Animalia } \\ \text { Phylum: } & \text { Arthropoda } \\ \text { Subphylum: } & \text { Crustacea } \\ \text { Clase: } & \text { Malacostraca } \\ \text { Orden: } & \text { Decapoda } \\ \text { Infraorden: } & \text { Brachyura } \\ \text { Familia: } & \text { Ocypodidae } \\ \text { Género: } & \text { Ucides }\end{array}$

\section{Ucides occidentalis (Ortmann, 1897)}

\section{Características biológicas de Ucides occidentalis}

Ucides occidentalis es una especie herbívora, especializada en hojas de mangle. Posee dimorfismo sexual, con machos de mayor tamaño y peso, mientras que las hembras poseen un pleon ancho con forma ovoide y cuatro pares de pleópodos con finas setas, en los machos el pleon es cuasi-triangular y tienen un único par de pleópodos de consistencia dura, adaptados para la reproducción (Barragán 1993, Muñiz \& Peralta 1983, Rivera \& Córdova 2010, Zambrano \& Aragón-Noriega 2016).

Nobili (1901) reportó la probable existencia de morfotipos en $U$. occidentalis, pero no pudo confirmar su conjetura. Actualmente, se conoce la existencia de dos morfotipos (i.e., homoquelos y heteroquelos), cada uno con dos variedades. En los cangrejos homoquelos las dimensiones de los propodios quelares son similares, mientras que, los heteroquelos presentan indistintamente un propodio quelar más grande (Zambrano \& Aragón-Noriega 2016). Los machos adultos de $U$. occidentalis tienen el mero del quelípedo tan largo que no se pueden movilizar sin mantenerlos lateralmente ubicados, lo cual le confiere una posición corporal característica para caminar y alimentarse (Wright 1968); por otra parte, en estos individuos se ha documentado malformaciones morfológicas en cefalotórax, propodios quelares y/o periópodos, de etiología desconocida (Zambrano 2017b).

\section{Reproducción de Ucides occidentalis}

La estrategia reproductiva de $U$. occidentalis consiste en la iteroparidad estacional y un periodo reproductivo prolongado, con desoves entre diciembre y mayo, lo cual se solapa con la época lluviosa de Ecuador (Cedeño 2013, Solano \& Moreno 2009, Tazan \& Wolf 2000, Zambrano 2016). En Perú se han observado reproducciones entre diciembre y abril, en tanto que, en El Salvador se reproduce casi todo el año con mayor intensidad entre febrero y septiembre (Rivera 2010a, Rujel 1996). La discrepancia aparente con las evidencias de El Salvador se debe a la metodología empleada, Rivera (2010a) utilizó el desarrollo gonadal como indicador del período reproductivo mientras que, los otros estudios se basaron en la presencia/ausencia de hembras ovígeras (Zambrano 2016), lo cual es más preciso en términos de reproducción efectiva.

La talla de madurez sexual morfométrica en machos es de 63.5 mm de ancho de cefalotórax (AC) con un intervalo de confianza (IC) entre 62.9 y $64.5 \mathrm{~mm} \mathrm{AC}$, mientras que, para hembras es de $57.8 \mathrm{~mm}$ AC ( $\mathrm{IC}=56.8$ - $59.6 \mathrm{~mm}$ AC). En contraste, la madurez fisiológica en machos es menor a la establecida por métodos morfométricos, siendo para machos de $61.3 \mathrm{~mm} \mathrm{AC}$ (IC= 60.9-62.1 $\mathrm{mm} \mathrm{AC}$ ) y de $49.3 \mathrm{~mm} \mathrm{AC} \mathrm{(IC=} \mathrm{47.4} \mathrm{-} \mathrm{50.0}$ mm AC) para hembras (Cedeño 2013).

Muñiz y Peralta (1983) mencionan que, los machos de $U$. occidentalis muestran diferencias notables en las dimensiones de los propodios quelares (PQ) después de la madurez sexual y en función de esa característica determinaron un punto de inflexión entre 46 y 50 mm AC para los PQ diestros; sin embargo, se sostiene que la inflexión no fue abrupta. Con base en la pendiente $(b=1.2)$ de las regresiones lineales realizadas por Muńiz y Peralta (1983) Muñiz \& Peralta (1983), se observa que los machos de $U$. occidentalis tienen un crecimiento somático alométrico positivo debido a que, $b>1$ (Hartnoll 1974) (Hartnoll, 1974).

Zambrano y Aragón-Noriega (2016) demostraron que los propodios quelares no son un carácter sexual secundario fidedigno para estimar madurez sexual en machos de $U$. occidentalis toda vez que el crecimiento alométrico es progresivo y no muestra un punto de inflexión o cambio en las fases de desarrollo (i.e., juvenil, adulto). Por tal razón, lo encontrado por Muñiz y Peralta (1983) fue coyuntural y numéricamente inconsistente.

La fecundidad media de $U$. occidentalis es de 195697 huevos hembra $^{-1}$ fluctuando entre 12847 y 385792 huevos hembra ${ }^{-1}$. La talla mínima de hembras ovígeras reportada fue $36.7 \mathrm{~mm}$ AC (Cedeño 2013). Cabe destacar que, las hembras de $U$. occidentalis se caracterizan por no participar en los combates altamente ritualizados para esta especie, principalmente en época reproductiva (Wright 1968).

\section{Crecimiento individual de Ucides occidentalis en el Golfo de Guayaquil}

El periodo de muda de $U$. occidentalis, en Ecuador, ha sido reportado entre julio y septiembre, pero es probable que la ecdisis ocurra durante todo el ańo y que los meses seńalados sean los más importantes para el proceso (Barragán 1993, Muñiz \& Peralta 1983). Cabe destacar que, se han observado cangrejos in situ en proceso de ecdisis (i.e., exoesqueleto blando o presencia de oxalato de calcio en la hemolinfa) durante el mes de octubre en los manglares del Golfo de Guayaquil. Aquello demuestra que, el periodo de muda es más amplio de lo reportado o que puede extenderse en al menos un mes. 
El crecimiento individual de Ucides occidentalis es noasintótico, indeterminado, con una curva en forma sigmoidea vertical invertida, con diferencias significativas entre sexos, siendo las hembras las que alcanzan primero el punto de inflexión (Zambrano 2017a, Zambrano et al. 2016, Zambrano et al. 2017). Varios trabajos se ha asumido que el crecimiento individual de $U$. occidentalis y $U$. cordatus es asintótico y utilizan el modelo de Von Bertalanffy (1938) para representar y comparar entre congéneres asumiendo que, los preceptos del modelo representan las características biológicas de las especies (Cedeño 2014a, Chalén 2004, Costa et al. 2014, Diele 2000, Diele \& Koch 2010, Pinheiro et al. 2005, Poma \& Bocanegra 1997, Rivera 2013).

\section{Características ecológicas de Ucides occidentalis}

Ucides occidentalis participa en la retención de nutrientes y materia orgánica en el sedimento del manglar, disminuyendo la pérdida de energía en el sistema por efecto de la dinámica de mareas (Twilley et al. 1997). Además, promueve la aireación del suelo durante la construcción de su madriguera, la cual tiene una profundidad ca. $2 \mathrm{~m}$ y es construida en las cercanías de una fuente de agua, con vegetación circundante de abundante fronda (Barragán 1993, Ordinola et al. 2010, Solano et al. 2010, Tazan \& Wolf 2000). Cabe destacar que, la profundidad de las madrigueras es variable entre regiones, por ejemplo en los manglares de San Pedro (Piura, Perú) se ha observado que se encuentran a una profundidad entre 0.33 y $0.53 \mathrm{~m}$, mientras que, en Costa Rica esta alrededor de 1.3 m (Alemán \& Ordinola 2017, Cabrera-Peńa et al. 1994).

Las madrigueras son individuales y cuando es invadida por otro cangrejo, el ocupante se puede retraer o exhibir el mero lateral al invasor; la segunda opción generalmente termina en un combate salvo que, la orientación del mero sea revertida, en ese caso, el invasor palpa al ocupante con los dáctilos de los periópodos y retrocede (Wright, 1968)

Se ha señalado escasa variabilidad genética de $U$. occidentalis al comparar tres zonas del Golfo de Guayaquil utilizando marcadores tipo AFLP (Ratti 2010). Estos resultados sugieren que se trata de una población compuesta por meta-poblaciones separadas por barreras físicas (e.g., granjas camaroneras, cuerpos de agua) lo cual correspondería a los conceptos de Levins (1969). Por lo tanto, la metapoblación de U. occidentalis es del tipo mosaico debido a que, se distribuye en parches discretos (relacionados al bosque de manglar en el continente e islas), entre los cuales existiría una migración generalizada, principalmente por exportación-retención larval, lo cual evidenciaría que no es una población local independiente (Harrison 1991, ValverdeValdés 1999).

La densidad poblacional media de U. occidentalis en el Golfo de Guayaquil es de 0.7 cangrejos $\mathrm{m}^{2}$, la cual se denota inferior a las reportadas para El Salvador (9 cangrejos $\mathrm{m}^{2}$ ) y Perú (4 - 9.6 cangrejos $\mathrm{m}^{2}$ ) (Cedeño 2014b, Poma \& Bocanegra 1997, Rivera 2010b). Sin embargo, las diferencias metodológicas influirían en estos contrastes debido a que, Cedeño (2014b) empleó cuadrantes de $5 \mathrm{~m}^{2}$, Poma y Bocanegra (1997) transectos perpendiculares al borde de los canales de mareas y Rivera (2010b) utilizó trampas de recolecta en un área de $400 \mathrm{~m}^{2}$.

La densidad media de madrigueras es variable de acuerdo con el autor y la región, en el Golfo de Guayaquil oscila de 0.96 -
1.38 madrigueras $\mathrm{m}^{2}$ (Cedeño 2014b) a 0.93 y 3.12 madrigueras $\mathrm{m}^{2}$ s sin estratificación hasta los $200 \mathrm{~m}$ hacia el interior del manglar (Mora 2015). En Perú, se han reportado densidades entre 1.0 y 3.1 madrigueras $\mathrm{m}^{2}$, con máximos al interior del manglar (Alemán \& Ordinola 2017, Ordinola et al. 2010). Es importante destacar que, no todas las madrigueras son habitadas (Cedeño 2014b), por lo tanto, la densidad media de madrigueras es un indicador sesgado de la densidad poblacional de $U$. occidentalis y con ella se sobrestima el número de cangrejos por unidad de área.

La proporción sexual de U. occidentalis en el Golfo de Guayaquil varía según los autores. Mora (2015) encontró mayor abundancia de machos y Cedeño (2014b) de hembras. En ambos trabajos la proporción sexual difirió entre sitios de muestreo, lo cual evidencia heterogeneidad espacial a microescala; sin embargo, diferencias metodológicas pueden afectar la comparación entre estimaciones, Mora (2015) trabajó con cuadrantes de $1 \mathrm{~m}^{2}$ y Cedeño (2014b) de $5 \mathrm{~m}^{2}$. No obstante, en áreas muestreadas en El Salvador, Costa Rica y Perú, consistentemente se han reportado mayores proporciones de machos, 2:1, 1.96:1, 1.5 2:1, respectivamente (Cabrera-Peña et al. 1994, Ordinola et al. 2010, Poma \& Bocanegra 1997, Rivera 2010b).

Las tallas medias poblacionales de $U$. occidentalis observadas en el Golfo de Guayaquil fueron 68.83 y $77.83 \mathrm{~mm}$ AC para machos y hembras, respectivamente, con máximas de 102.38 mm AC para hembras y $142 \mathrm{~mm}$ AC para machos (Cedeño 2014b, Zambrano 2017a, Zambrano et al. 2016), sin evidencia de una estratificación de tallas poblacionales hacia el interior del manglar (Mora 2015, Ordinola et al. 2010), lo cual sugiere heterogeneidad espacial de las tallas.

Las tallas medias poblacionales de U. occidentalis en el Golfo de Guayaquil son superiores a lo reportado en Costa Rica y Perú. En el primer caso, las tallas en el rango de 46-51 mm AC para hembras y de 51 - $56 \mathrm{~mm}$ AC para machos, mientras que, las máximas son 60.8 y 84.5 mm AC para hembras y machos, respectivamente (Cabrera-Peńa et al. 1994). En el segundo caso, las tallas medias son $66.6 \mathrm{~mm}$ AC para hembras y $74.3 \mathrm{~mm}$ AC para machos, mientras que, las máximas son 96 y $104 \mathrm{~mm} \mathrm{AC}$ para hembras y machos, respectivamente (Ordinola et al. 2010, Poma \& Bocanegra 1997).

\section{Manejo pesquero de Ucides occidentalis, en el Golfo de Guayaquil}

En Ecuador, las herramientas legales para el manejo pesquero de Ucides occidentalis se denominan "Acuerdos Ministeriales (AM)", los cuales son publicados en el Registro Oficial para su archivo y difusión. Los AM son elaborados, aprobados, modificados o derogados por la función administrativa responsable del ordenamiento pesquero, según el escenario social, económico, político y/o sus combinaciones. Para sustentar técnicamente los AM es deseable, pero no indispensable ni sujeto a considerar plenamente, el criterio del Instituto Nacional de Pesca para orientar las acciones legales hacia el aprovechamiento sustentable de los recursos.

La pesquería de $U$. occidentalis ha sido regulada desde 1986 cuando se expidió el reglamento de veda para la captura, procesamiento y comercialización interna y externa de esta especie (AM \#373); sin embargo, las medidas de manejo se han ido actualizando con el afán de aprovechar sustentablemente el recurso. Paralelamente a los AM existen los "Planes de Manejo 
(PM)", los cuales corresponden a documentos legales enfocados a administrar integralmente, zonas específicas con diversos fines (e.g., pesqueros, turísticos, reservas naturales).

El "acuerdo para el uso sustentable y custodia del manglar..." establecido en el año 2000 (AM \#172 del 05 de enero del 2000) promueve concesionar áreas delimitadas de manglar a organizaciones pesqueras. Con base en ese AM se elaboran los PM correspondientes, los cuales se sujetan a consideración por las autoridades competentes y procurarán el aprovechamiento sustentable de los recursos naturales.

El arte de pesca permitido, en la pesquería de $U$. occidentalis, es una varilla metálica con un extremo en forma de mango y el otro en forma de "U", la cual sirve para acercar el cangrejo a la entrada de la madriguera y capturarlo manualmente usando un guante de tela (Cedeño et al. 2012, Moreno \& Ruiz 2010); sin embargo, en décadas pasadas no existía ese arte de pesca y se utilizaba únicamente la mano y el guante (Barragán 1993).

El uso de mayas de nylon dispuestas en la entrada de la madriguera y fijadas con raíces de mangle (i.e., método conocido como trampas) está prohibido desde el 2007 (AM \#204 del 29 de noviembre 2007). Sin embargo, este método continúa aplicándose ilegalmente y su impacto sobre la población de $U$. occidentalis, no ha sido cuantificado hasta el momento, por lo que se recomienda la evaluación de este arte de pesca.

La pesquería de $U$. occidentalis es selectiva hacia los machos (Barragán 1993, Cedeño et al. 2012, Zambrano 2014) debido a la prohibición de capturar, procesar y comercializar hembras (AM \#030 del 04 de julio del 2003). La talla mínima actualmente es $75 \mathrm{~mm}$ de ancho de cefalotórax (AM \#004 del 13 de enero del 2014), pero anteriormente era $60 \mathrm{~mm}$ AC (AM \#030 del 04 de julio del 2003).

Con el fin de proteger el momento de mayor actividad reproductiva de $U$. occidentalis, existe un cierre pesquero (veda) anual, entre el 1 y 31 de marzo desde el 2014 (AM \#004 del 13 de enero del 2014), el cual anteriormente regía entre el 15 de enero y 15 de febrero (AM \#016 del 3 de febrero del año 2004). La disposición del mes de veda ha sido objeto de fuerte debate entre pescadores, técnicos y autoridades, debido a las diferencias reproductivas entre zonas de manglar en el Golfo de Guayaquil.

El periodo de muda de $U$. occidentalis se protege con la prohibición de pescar entre el 15 de agosto y 15 de septiembre (AM \#016 del 3 de febrero del ańo 2004); esta medida tiene un propósito añadido de salud pública debido a que, durante la ecdisis el cangrejo no es apto para el consumo humano (Solano \& Moreno 2009) porque puede causar daños intestinales y reacciones alérgicas a los consumidores (Muñiz \& Peralta 1983).

A nivel local, las organizaciones pesqueras tienen reglamentos internos de obligado cumplimiento que rigen su actividad, incluyendo medidas de manejo pesquero que, en caso de incumplimiento, los infractores son sancionados administrativamente por la organización. Este tipo de medidas de manejo y sanciones varían espacial y temporalmente de acuerdo con la organización pesquera de la que se trate, por ejemplo, existe la prohibición de pescar en determinados días de la semana (e.g., domingos) así como, una talla mínima de captura local, la cual es superior a la nacional.

\section{Operatividad de los pescadores y comercialización de Ucides occidentalis, en el Golfo de Guayaquil}

Existe un vacío de conocimiento científico y documentado sobre la operatividad en la pesquería de $U$. occidentalis, por ello, este aparatado expone de forma ordenada el conocimiento acumulado entre 2011 y 2014 mediante observaciones directas y entrevistas a pescadores en el Golfo de Guayaquil. La pesca de $U$. occidentalis se realiza principalmente en sitios de pesca del Golfo de Guayaquil, que abarca las provincias de Guayas y El Oro, bajo distintos regímenes como reservas ecológicas, concesiones de manglar y áreas de libre acceso (Solano et al. 2010, Zambrano 2014).

La Federación Nacional de Cooperativas Pesqueras del Ecuador (FENACOPEC) reportó, en 2014, que existen 3383 cangrejeros registrados que tienen como sustento económico la pesquería de $U$. occidentalis; sin embargo, ese número no incluye a los "cangrejeros independientes" (personas que no están registradas en alguna organización pesquera) ni a los hijos de los pescadores, menores de edad, que también pescan.

Para capturar individuos de $U$. occidentalis es común el desplazamiento hacia los sitios de pesca y puertos de desembarque considerando la dinámica de mareas. Los medios de transporte son la bicicleta, motocicletas, embarcaciones a remo o con motor fuera de borda, cuyo uso dependerá de la distancia a recorrer por los pescadores y su ubicación espacial. En este sentido, los pescadores de la isla Mondragón se desplazan hacia el sitio de pesca mediante embarcaciones a remo o con motor fuera de borda; por otra parte, en la Reserva Ecológica Manglares Churute (REMCH) el desplazamiento se puede realizar mediante algún transporte terrestre y posteriormente sobre alguna embarcación.

Los pescadores usan una "vestimenta especial" (Barragán 1993) y dirigen su esfuerzo hacia las madrigueras de los machos de U. occidentalis, identificándolas según las huellas sobre el lodo cercano a su entrada y el diámetro de su abertura; consideran que las huellas más profundas y un mayor diámetro de la entrada son características típicas de las madrigueras de los machos. Esta percepción influye en el proceso de pesca (i.e., direccionamiento del esfuerzo a madrigueras específicas) y también ocurre en la pesquería de $U$. cordatus en Brasil (Alves et al. 2005).

La diferenciación visual entre madrigueras de machos y hembras no siempre es efectiva y está sujeta a factores ambientales y biológicos de $U$. occidentalis. En época lluviosa y mareas de sicigia, las precipitaciones pueden borrar o modificar las huellas de los cangrejos; además, durante el periodo reproductivo existen movimientos masivos de individuos sobre el lodo que provocan distintas huellas de cangrejos en las entradas de las madrigueras. Esto afecta la percepción de los pescadores, quienes generalmente asumen es infalible.

La efectividad del cangrejero para identificar visualmente las madrigueras de $U$. occidentalis según el sexo proviene de un proceso no aleatorio, en el cual se selecciona a priori las madrigueras más grandes que, generalmente corresponderían a individuos machos que son los que alcanzan las tallas mayores; por ello, el éxito de la percepción visual puede ser alto, tal como se evidenció para $U$. cordatus en Brasil (Alves et al. 2005) y provoca una selectividad respecto a las tallas de captura que varía entre personas (Zambrano 2014). La efectividad de la percepción de 
los pescadores para dirigir su esfuerzo pesquero a madrigueras de machos no ha sido evaluada, pero se asume que influye en la actividad pesquera y los desembarques.

La operatividad de la pesquería de $U$. occidentalis está determinada por factores físicos, biológicos y ambientales tales como, la humedad del suelo, la cantidad de raíces del mangle circundante, la intensidad y temporalidad de las precipitaciones, la dinámica de mareas y la experiencia del pescador. Existe un único trabajo conocido que relaciona el factor ambiental con la pesquería de $U$. occidentalis y reportó que, la época del año (e.g., lluviosa) y la dinámica de mareas influye en la variabilidad de la tasa de captura, lo cual repercute en la estimación de los desembarques (Villegas 2012).

En suelos con poca humedad ("resecos”) es más difícil la extracción de cangrejos, con un mayor costo energético y una menor pesca debido al agotamiento físico del pescador. Por ello, estos sitios únicamente son trabajados cuando, por algún factor (e.g., precipitaciones, sicigias) la humedad del suelo aumenta y disminuye la dificultad de la pesca. La influencia de la humedad del suelo sobre la selección de los sitios de pesca y la captura de U. occidentalis no ha sido evaluada, sin embargo, es importante establecer si corresponde a un factor en la rotación entre sitios de pesca.

Los sitios con demasiadas raíces de mangle circundantes a las madrigueras obstaculizan las maniobras del pescador para extraer el recurso, lo cual conduce a la rotación de entre áreas de pesca con escasa presencia de raíces de mangle y los sitios con gran cantidad, estos últimos son visitados únicamente cuando por algún factor no se puede pescar en otros lugares. Durante precipitaciones copiosas el suelo del manglar se cubre de agua, lo que impide localizar madrigueras y posibles raíces o ramas de mangle que puedan causar daño al pescador. Por ello, durante la época lluviosa la pesca de $U$. occidentalis está determinada por las precipitaciones en las áreas de manglar.

La dinámica de mareas (i.e., pleamar, baja mar, sicigias y cuadraturas) permite acceder a los sitios de pesca descubiertos en baja mar, pero también influye en el acceso a los puertos de desembarque, según la fisiografía de la zona; por lo tanto, ese factor ambiental puede influir antes, durante y después de la pesca de $U$. occidentalis. La experiencia del pescador determina la cantidad de recurso extraído en un tiempo establecido y/o en la selectividad de su esfuerzo a la captura de individuos de cierta talla preferida por el pescador. En virtud de lo anterior es necesario evaluar numéricamente la experiencia del pescador para definir si es un factor determinante que deba ser considerado en la estandarización de las capturas, esfuerzo pesquero y tallas comerciales de $U$. occidentalis.

Los cangrejos capturados son aglomerados para su venta, generalmente a intermediarios, en paquetes comerciales conocidos como "atados" o "sartas" y a su vez, el conjunto de cuatro atados es denominado "plancha”. Actualmente, cada atado estándar consta de 12 individuos, pero se pueden encontrar variantes (e.g., 22 cangrejos atado ${ }^{-1}$ ). En décadas pasadas los atados tenían 9 o 16 cangrejos, las sartas de 12 cangrejos, y existían además las "canastas" que contenían cinco individuos (Barragán 1993). El precio promedio semanal de cada atado estándar, en el primer eslabón de la cadena productiva, fueron 6.48 dólares en 2012, destacando que los precios más altos se dan entre jueves y domingo (Flores 2012).
Previo a las vedas existe un incremento en el precio de atados de cangrejos (Flores 2012), lo cual también sucede en épocas festivas populares (e.g., semana santa, carnaval) donde el precio puede duplicarse o incluso triplicarse para el consumidor final. El precio de cada atado estándar de cangrejo depende principalmente de la talla de los individuos, zona de venta y longitud de la cadena de valor. Existen diferencias en el precio, incluso de dos dólares atado ${ }^{-1}$, en el mismo sitio de expendio (e.g., mercado "Caraguay" en Guayaquil).

Una alternativa para la comercialización de $U$. occidentalis es la venta de la denominada "pulpa" de cangrejo, lo cual corresponde al expendio de la musculatura o carne del cangrejo dispuesta en un recipiente plástico. Aquello, generalmente se acompańa del órgano perigástrico, anteriormente conocido como hepatopáncreas (Cervellione et al. 2017) y localmente llamado "gordura", así como, de propodios quelares. Convencionalmente, la pulpa de cangrejo es extraída por los familiares de los pescadores, quienes generalmente la venden congelada bajo pedido, siendo factible la instalación de una planta procesadora para aumentar el valor agregado de U. occidentalis (Cabrera 2011); por otra parte, existen empresas que procesan, enlatan y expenden la pulpa de cangrejo en el mercado interno de Ecuador.

Un problema latente en el consumo de $U$. occidentalis radica en que existen reportes de la presencia de metales pesados (i.e., cadmio, plomo, cromo, mercurio, arsénico) en el exoesqueleto, órgano perigástrico y músculo de $U$. occidentalis (Ayala-Armijos et al. 2015, Chuquimarca 2015, Ecobiotec 2009, Feys 2013, Sánchez 2017, Siavichay 2013). Esta situación es un problema potencial de salud pública y ambiental que no ha sido considerado por las autoridades sanitarias. Por otra parte, en la pulpa de $U$. occidentalis se ha encontrado nitrógeno básico volátil y organismos aerobios psicrófilos, lo cual indica un proceso de descomposición y proliferación bacteriana por un congelamiento inadecuado (Ecobiotec 2009). Debido a que, el procesamiento de las partes comestibles de $U$. occidentalis (i.e., músculo y órgano perigástrico) es un tema de interés económico, social y de salud pública, se deben realizar estudios de inocuidad en el procesamiento, cadena de frío y venta de Ucides occidentalis, así como, de las fuentes de descarga de metales pesados al ambiente y su influjo sobre otras especies.

\section{Desembarques y tallas comerciales de Ucides occidentalis en el Golfo de Guayaquil}

Los registros pesqueros de $U$. occidentalis que posee el INP están disponibles desde el 2004, con un vacío de información entre 2005 y 2008 (Fig. 2). La información, hasta el 2010, se refiere a los puertos pesqueros de las comunidades 6 de Julio, Balao, Puerto Baquerizo (provincia del Guayas), Hualtaco, Jelí, Bolívar (provincia de El Oro). Esos puertos son considerados los principales en la pesquería de $U$. occidentalis en el Golfo de Guayaquil, aportando entre cuatro y casi ocho millones de cangrejos por ańo hasta el 2010 (Solano 2011, Solano et al. 2010, 2012).

A partir del 2011, los niveles de desembarques corresponden a registros realizados por pescadores de las organizaciones pesqueras que colaboran con el INP en el seguimiento participativo de la pesquería (ciencia ciudadana). En 2011 se estimó un desembarque cercano a 1.4 millones de cangrejos, pero posteriormente existió una reducción entre 51.44 y $64.55 \%$ en los desembarques 
del 2012 y 2013, respectivamente. Aquello está relacionado con el descenso en el número de organizaciones que presentaron datos, así como, el promedio de meses con información (Fig. 2).

El descenso en los desembarques de U. occidentalis de los dos últimos años ha sido reportado previamente y se puede relacionar con la disminución de la captura por unidad de esfuerzo (Cedeño et al. 2012, Zambrano 2014, Zambrano \& Solano 2014). Este descenso también puede ser resultado de medidas de manejo adoptadas por las organizaciones pesqueras (e.g., menor lapso laboral) que reducen la pesca.

Este trabajo no descarta signos de agotamiento del recurso, influenciado por la intensidad pesquera realizada previa al
2011, pese a que otros estudios mencionan la inexistencia de sobrepesca de crecimiento y reclutamiento para $U$. occidentalis (Cedeño 2014a, 2014b, Cedeño et al. 2012). El descenso en los desembarques de $U$. occidentalis también ha sido observado en Perú entre 1980 y 1994 (Ordinola et al. 2010).

En conjunto, todos los años presentaron niveles de desembarque de $U$. occidentalis con una tendencia intra-anual similar, generando un patrón que muestra un descenso de los desembarques en enero-febrero y agosto-septiembre; además, se observa una tendencia negativa del desembarque entre marzo y julio, un aumento en octubre, el descenso en noviembre y otro aumento en diciembre (Fig. 3). Estas variaciones podrían

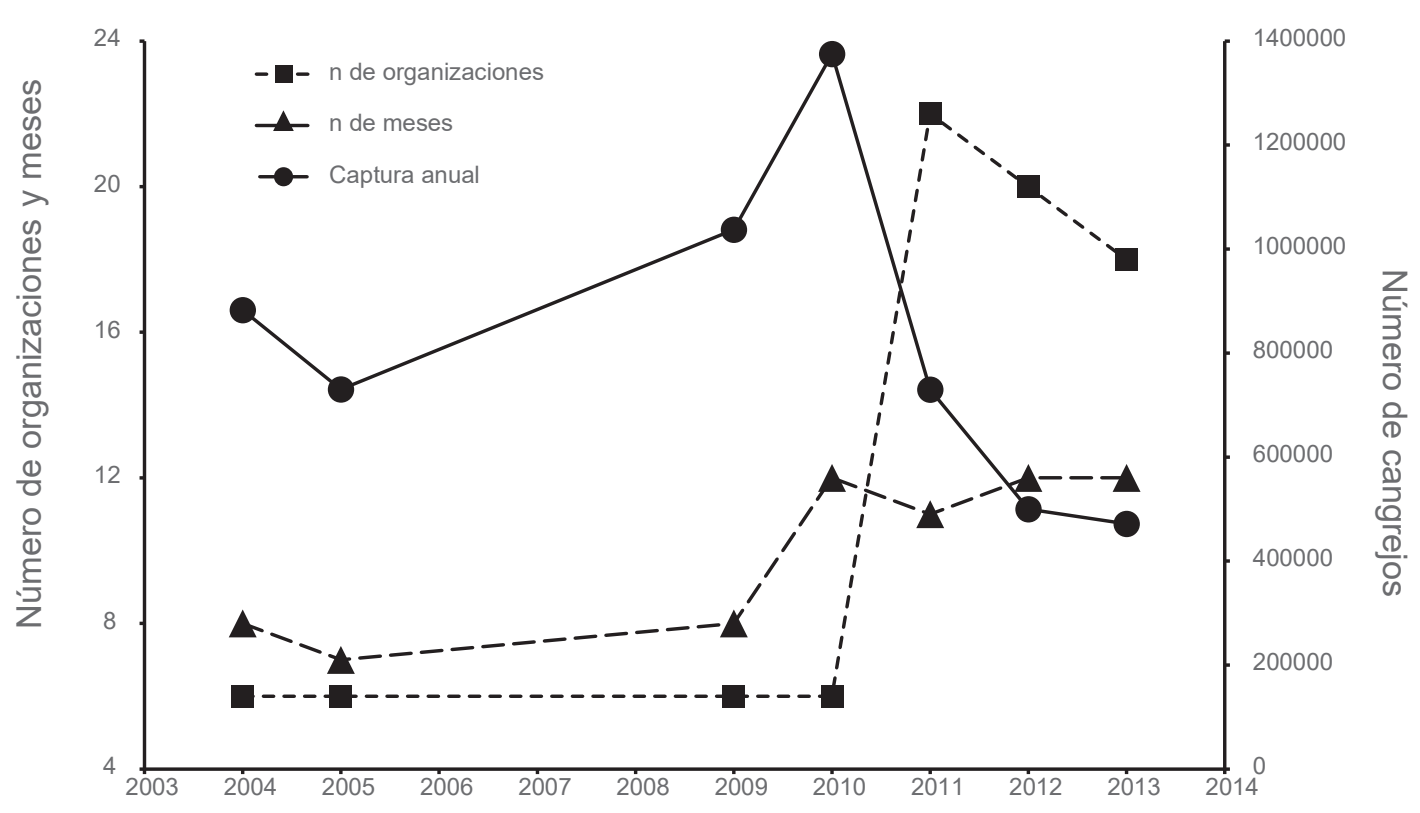

Figura 2. Desembarque anual (número de individuos), número de organizaciones pesqueras que presentaron información y promedio de meses con información sobre captura de Ucides occidentalis (Ortmann, 1897) en el Golfo de Guayaquil, Ecuador.

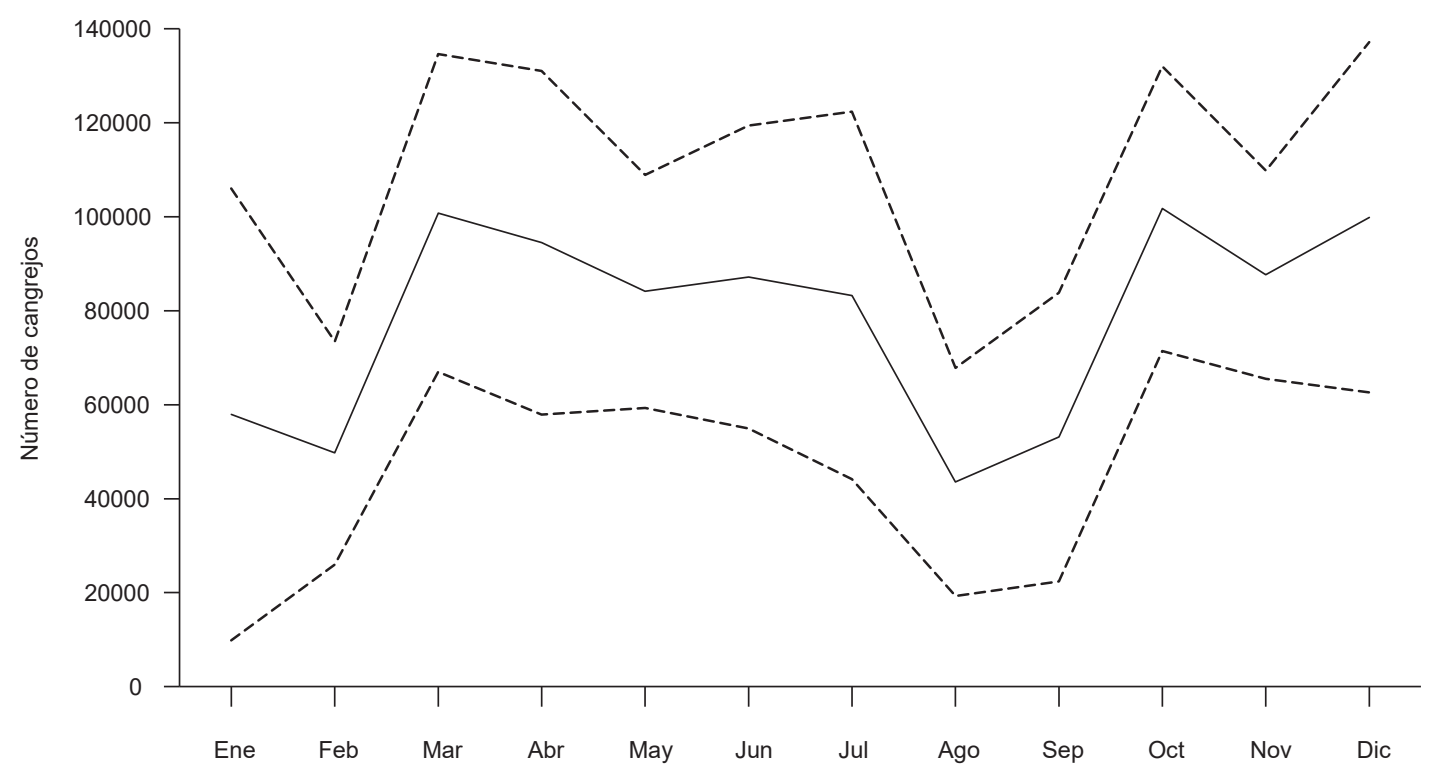

Figura 3. Patrón intra-anual del desembarque (número de individuos) de Ucides occidentalis (Ortmann, 1897) registrado en el Golfo de Guayaquil, Ecuador, durante el periodo 2004-2005 y 2009-2013. 
explicarse porque la veda reproductiva que regía entre enero y febrero reducía a la mitad el tiempo disponible para la pesca y de igual manera para agosto-septiembre por la veda de muda.

El descenso observado entre marzo y julio podría deberse a un agotamiento paulatino del stock pescable de $U$. occidentalis, el cual se "recupera" durante el periodo de muda, lapso que coincide con los meses de mayor reclutamiento considerados entre junio y septiembre (Cedeńo 2014a). Por otra parte, la captura por unidad de esfuerzo reportada en trabajos anteriores muestra un descenso hacia julio, lo cual influye directamente en los desembarques totales estimados (Zambrano 2014, Zambrano \& Solano 2014).

Solano et al. (2010) reportaron que, los mayores desembarques de $U$. occidentalis se encontraron dos meses posteriores a la veda reproductiva, y Solano (2011) menciona que, la demanda del mercado también influye en las capturas comerciales. Cabe destacar que, no se cuenta con estudios de mercado que indiquen los meses de mayor o menor demanda y debido a que, las vedas restringen la pesquería, el aumento de los desembarques posterior a estos periodos se considera normal. Es necesario resaltar que, aparentemente, las vedas sirven para la recuperación natural del recurso debido a que, los picos de capturas posteriores a las vedas son equiparables.

La evolución mensual de la captura de $U$. occidentalis, entre 2009 y 2013, denota variabilidad intermensual e interanual en cuanto al número de cangrejos capturados. En el periodo 2009 2010 se encontró el mayor desembarque mientras que, en 2011 - 2013 fue observó un 50\% menor y una captura estandarizada (captura mensual/número de organizaciones) promedio por debajo de 3000 cangrejos mes $^{-1}$ organización $^{-1}$ (Fig. 4).

La tendencia (media móvil de tres meses) de la captura estandarizada, mostró periodos contrastantes en el número de cangrejos capturados, desde 2009 a 2013, y una baja pero estable captura estandarizada (Fig. 5). Esta condición no se debería forzosamente a una reducción del tamaño poblacional de $U$. occidentalis, considerando el incremento de la talla mínima legal y media de captura, lo cual influye en la selección de individuos con mayor talla, peso y aprecio comercial. En este sentido, es

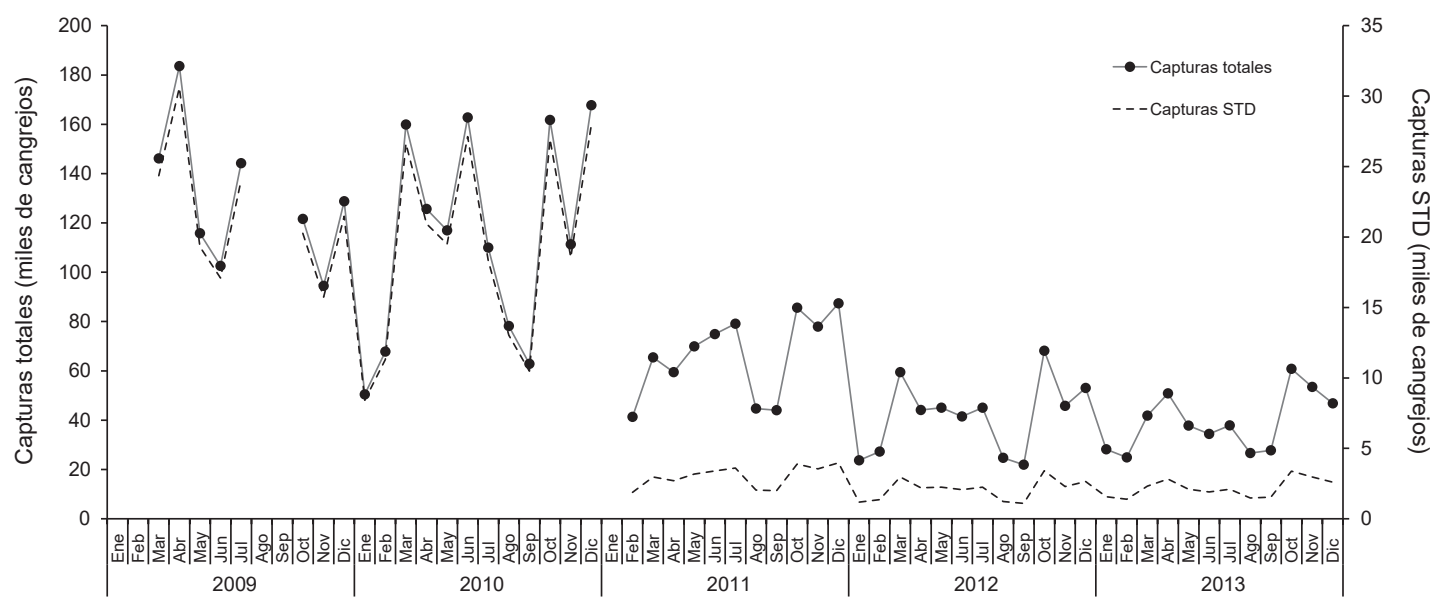

Figura 4. Evolución mensual de la captura de Ucides occidentalis (Ortmann, 1897) (línea segmentada) y captura estandarizada en cangrejos capturados mensualmente por organización pesquera (línea continua) del Golfo de Guayaquil.

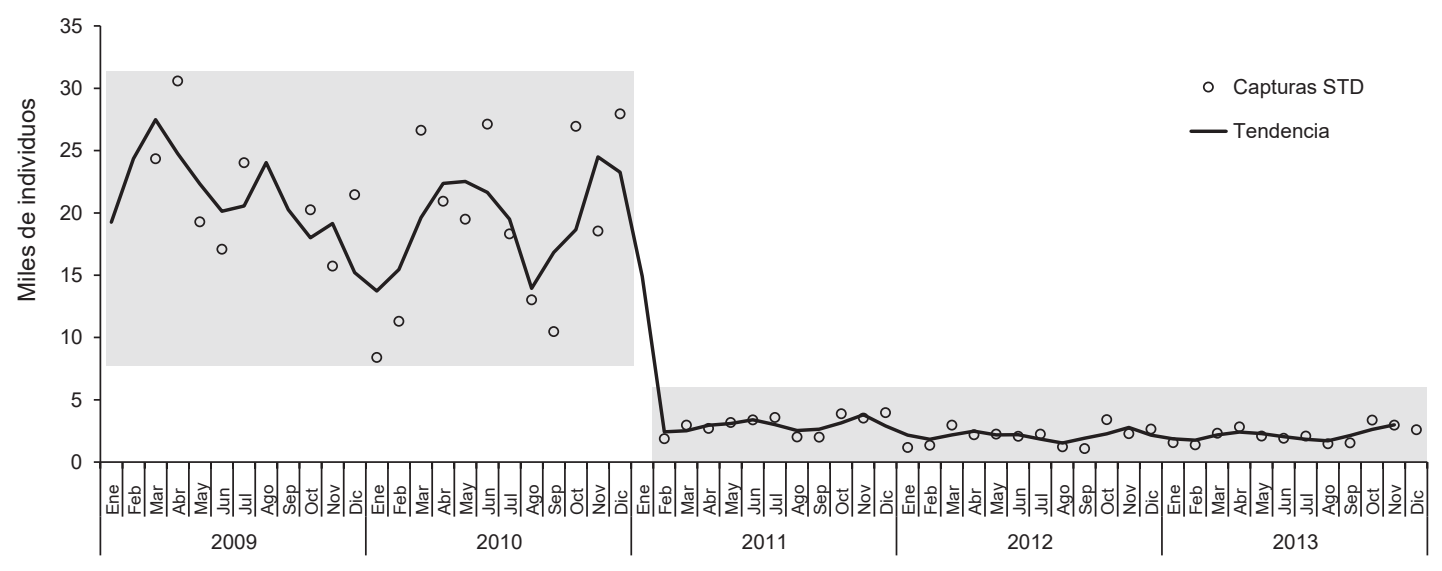

Figura 5. Evolución y tendencia de la captura estandarizada mensual de Ucides occidentalis (Ortmann, 1897) en el Golfo de Guayaquil durante el periodo 2009-2013. Sombreado ejemplifica periodos diferenciados de captura estandarizada. 


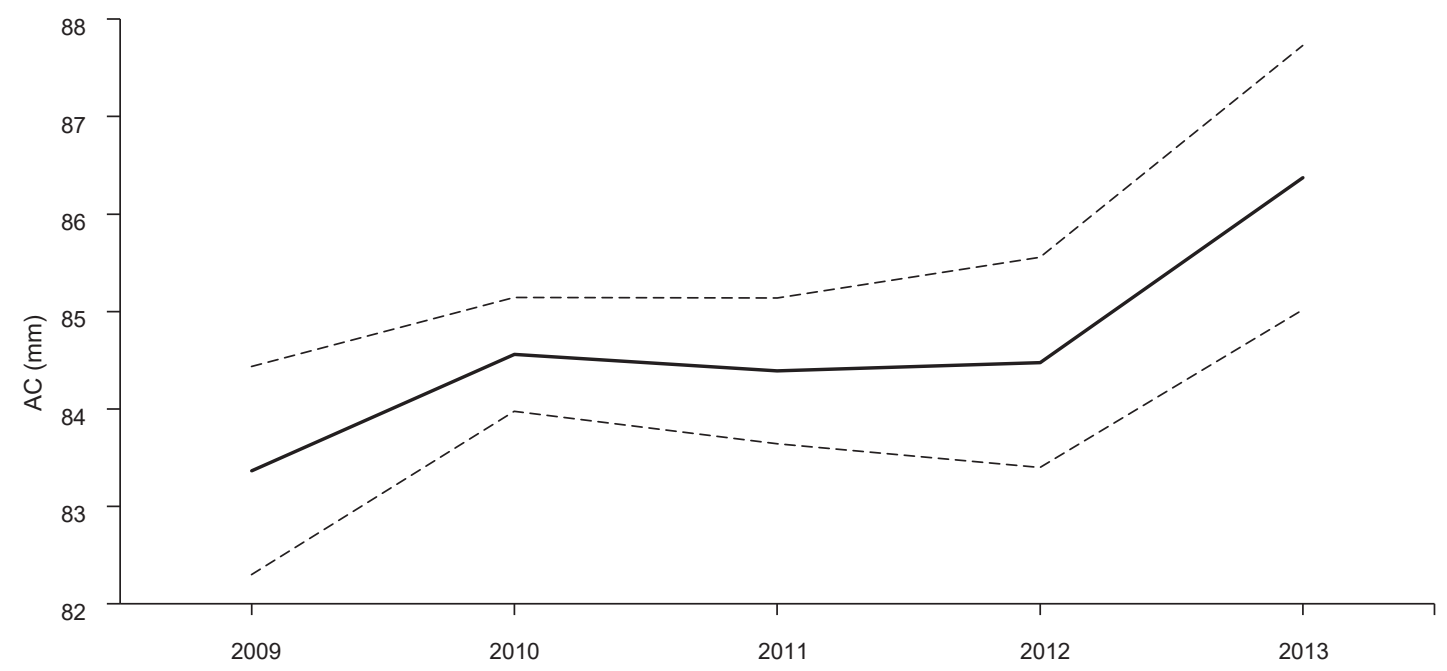

Figura 6. Variación inter anual de la talla media de captura comercial [(AC) (línea solida)] de Ucides occidentalis (Ortmann, 1897) en el Golfo de Guayaquil, Ecuador, con sus intervalos de confianza (líneas segmentadas).

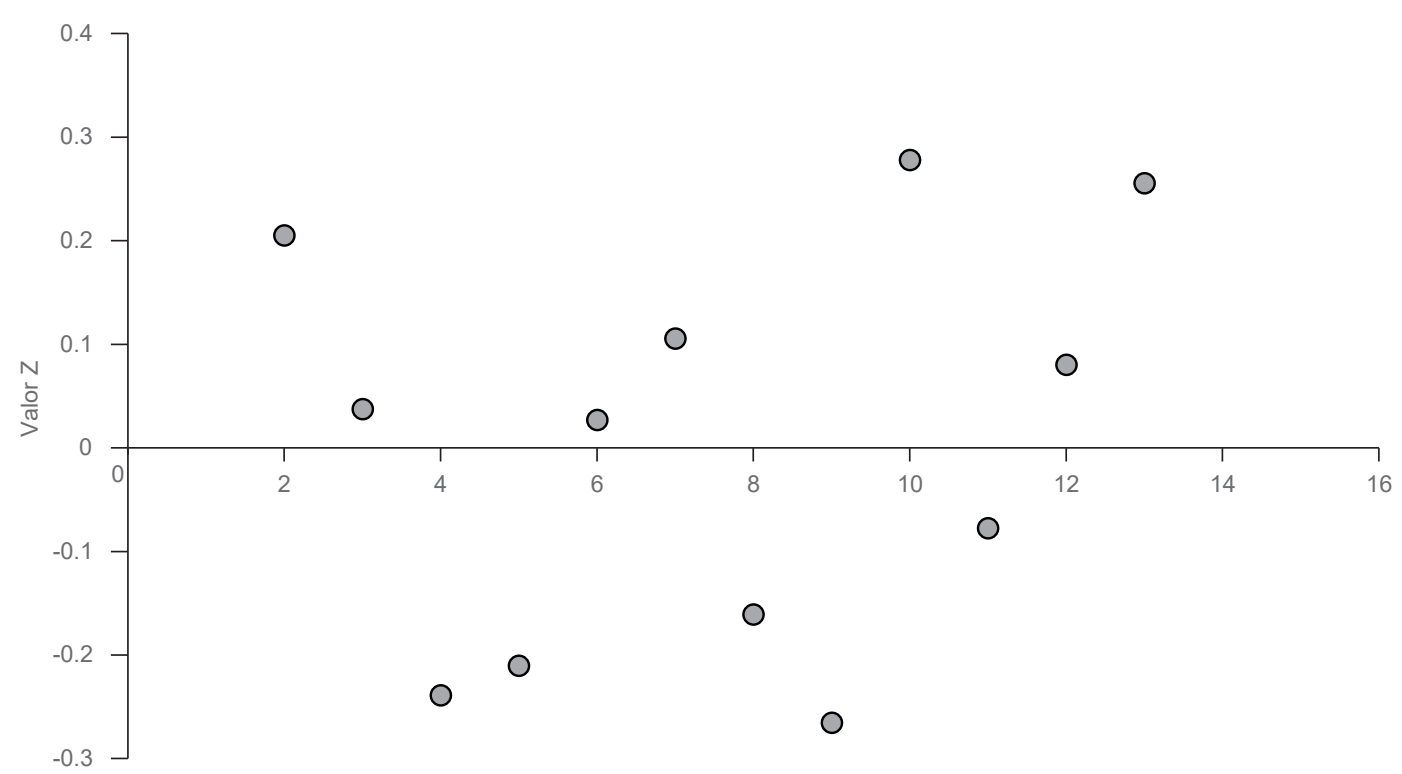

Figura 7. Dispersión de los valores Z mensuales correspondientes a las tallas medias comerciales, según los datos entre 2004 y 2013 de Ucides occidentalis (Ortmann, 1897) para el Golfo de Guayaquil, Ecuador.

necesario la construcción de series temporales de datos de captura a largo plazo, para evaluar permanentemente su evolución y pronosticar escenarios de manejo bajo diferentes condiciones.

La talla media comercial de $U$. occidentalis presentó una tendencia positiva desde el 2009, aumentando en 3.48\% (Fig. 6). Según los datos comerciales de Muñiz y Peralta (1983) obtenidos de puerto El Morro, entre 1979 - 1980, la talla media de captura en esa época fue de $58.38 \mathrm{~mm}$ AC, lo cual equivale a un incremento del $32.41 \%$ al 2013 . El incremento de la talla de captura se puede deber a un acto de conciencia del pescador por conservar el recurso y a la vez, obtener un mayor rédito económico; a su vez, otro factor que podría influir es la facilidad que brinda la extracción de cangrejos grandes por encontrarse en madrigueras de mayor diámetro (Solano 2011, Solano et al. 2010, Zambrano 2014). El presente trabajo considera que la talla mínima de captura (60 mm AC) no influencia el aumento de la talla media comercial debido a que, en el 2011, los pescadores sugieren aumentar la medida de manejo según su realidad (Solano 2011).

En 2014, con base en los argumentos de los pescadores, se aumentó la talla mínima de captura a $75 \mathrm{~mm}$ AC, a sabiendas que la talla media comercial posee un valor superior. El presente trabajo revela que los intervalos de confianza están por encima de $80 \mathrm{~mm}$ AC, lo cual implica que la talla mínima de captura se puede aumentar al menos en $5 \mathrm{~mm}$ AC. Las tallas medias comerciales de $U$. occidentalis varían espacialmente y existen áreas como Churute que muestran tallas promedio cercanas a 75 mm AC por lo que, un aumento en la talla mínima de captura tendría implicaciones en los niveles de desembarques (Cedeño et al. 2012, Zambrano 2014, Zambrano \& Solano 2014). 
Durante todo el año tallas medias comerciales de $U$. occidentalis son similares entre meses debido a que, los "valores $Z$ " son $p<0.5$ (Fig. 7). Aquello demostraría que la veda de muda, aparentemente, no influye en la talla comercial; sin embargo, este punto debe ser revisado con mayor profundidad debido a que, se desconoce el efecto de la veda a nivel poblacional y a su vez, su influjo en la pesquería.

\section{Literatura citada}

Acuerdo Ministerial \#373. 1986. Publicado en el Registro oficial \#489, el 30 de julio de 1986. República del Ecuador. https://www. registroficial.gob.ecl

Acuerdo Ministerial \#172. 2000. Publicado en el Registro oficial \#365, el 20 de enero del 2000. República del Ecuador. https:// www.registroficial.gob.ecl

Acuerdo Ministerial \#030. 2003. Publicado en el Registro oficial \#130, el 22 de julio del 2003. República del Ecuador. https://www. registroficial.gob.ecl

Acuerdo Ministerial \#016. 2004. Publicado en el Registro oficial \#284, el 03 de marzo del 2004. República del Ecuador. https:// www.registroficial.gob.ecl

Acuerdo Ministerial \#004. 2014. Publicado en el Registro oficial \#175, el 03 de febrero del 2014. República del Ecuador. https:// www.registroficial.gob.ecl

Alava J.J., A. Lindop \& J. Jacquet. 2015. Marine fisheries catch reconstructions for continental Ecuador: 1950-2010. University of British Columbia, Vancouver, Canada (UBC Fisheries Centre Working Paper \#2015-34): 1-25.

Alemán S., \& E. Ordinola. 2017. Ampliación de la distribución sur de Ucides occidentalis (Decapoda: Ucididae) y Cardisoma crassum (Decapoda: Gecarcinidae). Revista Peruana de Biología 24(1): 107-110. http://dx.doi.org/10.15381/rpb. v24i1.13110

Alves R.R.N., A.K. Nishida \& M.I.M. Hernández. 2005. Environmental perception of gatherers of the crab "caranguejo-uça" (Ucides cordatus, Decapoda, Brachyura) affecting their collection attitudes. Journal of Ethnobiology and Ethnomedicine 1(10): 1-8. https://doi.org/10.1186/1746-4269-1-10

Ayala-Armijos H., J. Pérez-Rodríguez, C. Quezada-Abad, A. SilvaOchoa \& L. Cortéz-Suárez. 2015. Cuantificación de metales pesados ( $\mathrm{Hg}, \mathrm{As}, \mathrm{Pb}$ y Cr$)$ en organismos acuáticos: cangrejo rojo (Ucides occidentalis). Revista Ciencia UNEMI 8(16): 54-60.

Barragán J. 1993. Biología del cangrejo de manglar, Ucides occidentalis, Ortmann, (Crustacea: Decapoda: Gecarcinidae). Revista de Ciencias del Mar y Limnología 3(1): 135-149.

Bright D.B., \& C.L. Hogue. 1972. A synopsis of the burrowing land crabs of the world and list of their arthopod symbionts and burrow associates. Contributions in Science 220: 1-58. https://www.biodiversitylibrary.org/part/241205

Cabrera-Peña J., F. Vives-Jiménez \& Y. Solano-López. 1994. Tamaños y proporción sexual de Ucides occidentales (Crustacea: Gecarnicidae) en un manglar de Costa Rica. Uniciencia 11: 97-99.

Cabrera C. 2011. Evaluación de factibilidad técnica financiera para la instalación de una planta procesadora de cangrejo. Tesis de Licenciatura, Escuela Superior Politécnica del Litoral, Guayaquil, Guayas, Ecuador. 67 p. http://www.dspace.espol. edu.ec/handle/123456789/17199

Cedeño I. 2013. Aspectos reproductivos del cangrejo rojo de manglar (Ucides occidentalis) en el Golfo de Guayaquil, Diciembre 2011-Abril 2012. Boletín Especial (Instituto Nacional de Pesca, Ecuador) 4(2): 1-14.

Cedeño I. 2014a. Dinámica poblacional y estado del stock de cangrejo rojo de manglar (Ucides occidentalis) en el Golfo de Guayaquil. Boletín Especial (Instituto Nacional de Pesca, Ecuador) 5(1): 75-88.

Cedeño I. 2014b. Tamaño del stock y estructura poblacional del cangrejo rojo de manglar (Ucides occidentalis) en los principales cangrejales del Golfo de Guayaquil, diciembre 2011, abril y noviembre 2012. Boletín Especial (Instituto Nacional de Pesca, Ecuador) 5(1): 13-35.

Cedeño I., M. Bravo, F. Solano, M. Peña \& R. Zambrano. 2012. Abundancia relativa y estructura de tallas de cangrejo rojo de manglar (Ucides occidentalis) en el Golfo de Guayaquil, Febrero 2011-Enero2012. Boletín Especial (Instituto Nacional de Pesca, Ecuador) 3(2): 1-32.

Cervellione F., C. McGurk \& W. Van den Broeck. 2017. "Perigastric organ": a replacement name for the "hepatopancreas" of Decapoda. Journal of Crustacean Biology 37(3): 353-355. https://doi.org/10.1093/jcbiol/rux020

Chace Jr, F.A., \& H.H. Hobbs Jr. 1969. The freshwater and terrestrial decapod crustaceans of the West Indies with special reference to Dominica. Bulletin of the United State National Museum 292(i-v): $1-258$

Chalén X. 2004. Parámetros de crecimiento de cangrejo rojo (Ucides occidentalis). Guayaquil. Reporte técnico, Instituto Nacional de Pesca, Guayaquil, Ecuador. 4 p.

Chuquimarca L. 2015. Contenido de metales pesados $(\mathrm{Hg}, \mathrm{Pb}$, $\mathrm{Cd}$ ), en el tejido blando del quelípedo y hepatopáncreas del cangrejo rojo (Ucides occidentalis), en tres localidades del perfil costero de la provincia de El Oro, 2014. Tesis de Licenciatura, Universidad Técnica de Machala, Machala, El Oro, Ecuador. 64 p. http://repositorio.utmachala.edu. ec/handle/48000/2833

Costa T.M.M., F.B. Pitombo \& A. Soares-Gomes. 2014. The population biology of the exploited crab Ucides cordatus (Linnaeus, 1763) in a southeastern Atlantic Coast mangrove area, Brazil. Invertebrate Reproduction \& Development 58(4): 259-268. https://doi.org/10.1080/07924259.2014.917126

Cruz M., N. Gabor, E. Mora, R. Jiménez \& J. Mair. 2003. The known and unknown about marine biodiversity in Ecuador (Continental and Insular). Gayana 67(2): 232-260. https://doi. org/10.4067/S0717-65382003000200010

Diele K. 2000. Life history and population structure of the exploited mangrove crab Ucides cordatus cordatus (Linnaeus, 1763) (Decapoda: Brachyura) in the Caeté Estuary, North Brazil. Tesis de doctorado, Universität Bremen, Bremen, Alemania. $116 \mathrm{p} . \quad$ http://researchrepository.napier.ac.uk/ output $/ 279261$

Diele K., \& V. Koch. 2010. Growth and mortality of the exploited mangrove crab Ucides cordatus (Ucididae) in N-Brazil. Journal of Experimental Marine Biology and Ecology 395: 171-180. https://doi.org/10.1016/j.jembe.2010.08.029

Ecobiotec. 2009. Evaluación de contaminación de concha prieta y cangrejo rojo. Reporte técnico, Quito, Pichincha, Ecuador. 40 p.

Feys J. 2013. Niveles de cadmio y plomo en el exoesqueleto del cangrejo rojo (Ucides occidentalis) del Golfo de Guayaquil (Las Loras-Puerto El Morro-Chupadores) y Machala (Puerto Bolívar). Tesis de Licenciatura, Universidad de Guayaquil, Guayaquil, Guayas, Ecuador. 49 p.

Flores J. 2012. Cadena de valor del cangrejo rojo en el Golfo de Guayaquil. Reporte técnico, Quito, Pichincha, Ecuador: 74 pp.

Harrison S. 1991. Local extinction in a metapopulation context: an empirical evaluation. Biological Journal of the Linnean Society 42: 73-88. https://doi.org/10.1111/j.1095-8312.1991. tb00552.x

Hartnoll R.G. 1974. Variation in growth pattern between some secondary sexual characters in crabs (Decapoda Brachyura). Crustaceana 27(2): 131-136.

Jiménez R. 1983. Diatomeas y silicoflagelados del fitoplancton del Golfo de Guayaquil. Acta Oceanográfica del Pacífico 2(2): 193-281. http://hdl.handle.net/1834/8291

Levins R. 1969. Some demographic and genetic consequences of environmental heterogeneity for biological control. Bulletin of the Entomological Society of America 15: 237-240. https:// doi.org/10.1093/besa/15.3.237

Magalhães H.F., E.M.C. Neto \& A. Schiavetti. 2012. Local knowledge of traditional fishermen on economically important crabs (Decapoda: Brachyura) in the city of Conde, Bahia State, Northeastern Brazil. Journal of Ethnobiology and Ethnomedicine 8(13): 1-10. https://doi.org/10.1186/17464269-8-13

Mora A. 2015. Estructura poblacional del cangrejo rojo (Ucides occidentalis) en un gradiente de inundación dentro de un bosque de manglar riverino (Isla Mondragón, Estuario rio Guayas). Tesis de Licenciatura, Escuela Superior Politécnica del Litoral, Guayaquil, Guayas, Ecuador. 69 p. http://www. dspace.espol.edu.ec/xmlui/handle/123456789/31064 
Moreno J., \& W. Ruiz. 2010. Situación Actual del Guariche Ucides occidentalis (Ortmann, 1897) en el Estuario del Río Chone, Manabí durante Abril 2009-2010. Boletín Científico y Técnico (Instituto Nacional de Pesca, Ecuador) 20(8): 16-35. http://hdl.handle.net/1834/4794

Muñiz L., \& B. Peralta. 1983. Aspectos biométricos de Ucides occidentalis Ortmann. Revista de Ciencias del Mar y Limnología 2(1): 151-170.

Ng P.K.L., D. Guinot \& P.J.F. Davie. 2008. Systema Brachyurorum: Part I. An annotated checklist of extant brachyuran crabs of the world. The Raffles Bulletin of Zoology 17. 1-286.

Nobili G. 1901. Viaggio del Dr. Enrico Festa nella Repubblica dell'Ecuador e regione vicine. XXIII. Decapodi e stomatopodi. Bollettino del Musei di Zoologia ed Anatomia Comparata della R. Universitá di Torino 16:1-58.

Oesterling M.J., \& C. Petrocci. 1995. The crab industry in Venezuela, Ecuador and Mexico: Implications for the Chesapeake Bay blue crab industry. Virginia, USA. 31 p.

Ordinola E., P. Montero, S. Alemán \& J. Llanos. 2010. El cangrejo de los manglares Ucides occidentalis (Ortman) en Tumbes, Perú. Primavera 2007. Informe Del Instituto del Mar del Perú 37(3-4): 151-159. http://biblioimarpe.imarpe.gob. pe:8080/handle/123456789/2017

Ortmann A.E. 1897. Carcinologishe Studien. Zoologischen Jahrbüchern. Abtheihmg Für Systematik, Geographie Und Biologie Der Thiere 10: 258-372.

Pinheiro M.A.A., A.G. Fiscarelli \& G.Y. Hattori. 2005. Growth of the mangrove crab Ucides cordatus (Brachyura, Ocypodidae). Journal of Crustacean Biology 25(2): 293-301. https://doi. org/10.1651/C-2438

Poma C.E., \& C.A. Bocanegra. 1997. Observaciones sobre la dinámica poblacional y pesquería del cangrejo de los manglares Ucides occidentalis (Decapoda, Brachyura, Ocypodidae) en Tumbes, Perú. Gayana Oceanológica 5(2): 95-105.

Ratti M. 2010. Optimización del sistema AFLP para determinación de la variabilidad genética de Ucides occidentalis en tres zonas de manglar del Golfo de Guayaquil. Tesis de Licenciatura, Escuela Superior Politécnica del Litoral, Guayaquil, Guayas, Ecuador. 61 p. http://www.dspace.espol.edu.ec/ handle/123456789/10280

Rivera C.G. 2010a. Biología reproductiva de Ucides occidentalis ("punches"), in: C.G. Rivera \& T.C. Cuéllar (Ed), El ecosistema de manglar de la Bahía de Jilisco (Sector Occidental), pp. 157-184. San Salvador, El Salvador, p. 157-184.

Rivera C.G. 2010b. Morfometría, abundancia y distribución de Ucides occidentalis ("punches"), in: C.G. Rivera \& T.C. Cuéllar (Ed), El ecosistema de manglar de la Bahía de Jilisco (Sector Occidental), pp. 137-155. San Salvador, El Salvador, p. 137-155.

Rivera C.G. 2013. Manejo Pesquero Sostenible de Ucides occidentalis ("punche"), recurso hidrobiológico de la Cuenca Baja del Río Lempa, Bahía de Jiquilisco, departamento de Usulután. Tesis de Maestría, Universidad de El Salvador, San Salvador, El Salvador. 107 p. http://ri.ues.edu.sv/id/eprint/3530

Rivera C.G., \& D.A. Córdova. 2010. Ecología alimentaria de Ucides occidentalis ("punches"), in: C.G. Rivera \& T.C. Cuéllar (Ed), El ecosistema de manglar de la Bahía de Jilisco (Sector Occidental), pp. 185-197. San Salvador, El Salvador, p. 185-197.

Rujel J. 1996. Biología reproductiva de Ucides occidentalis "cangrejo de los manglares" en el litoral de Tumbes, Perú 1996. Tesis de Maestría, Universidad Nacional de Trujillo, Trujillo, La Libertad, Perú. 105 p.

Sánchez A. 2017. Determinación de la concentración de plomo y arsénico presente en el tejido blando del cangrejo que se expende en el mercado El Arenal de la ciudad de Cuenca. Tesis de Maestría, Universidad del Azuay, Cuenca, Azuay, Ecuador. 40 p. http://dspace.uazuay.edu.ec/handle/datos/6994

Schubart C.D., \& J.A. Cuesta. 2010. Phylogenetic relationship of the Plagusiidae Dana, 19854 (Brachyura), with description of a genus and recognition of Percnidae Stevčić, 2005, as an independent family. Studies on Brachyura 1851: 279-299.

Shih H.-T., P.K.L. Ng, P.J.F. Davie, C.D. Schubart, M. Türkay, R. Naderloo, D. Jones, \& M.-Y. Liu. 2016. Systematics of the family Ocypodidae Rafinesque, 1815 (Crustacea: Brachyura), based on phylogenetic relationships, with a reorganization of subfamily rankings and a review of the taxonomic status of Uca Leach, 1814, sensu lato and its subgenera. Raffles Bulletin of Zoology 64: 139-175.

Siavichay B. 2013. Determinación de Cadmio y Plomo en el tejido blando, hepatopáncreas del cangrejo rojo (Ucides occidentalis) y sedimento de la Reserva Manglares Churute. Tesis de Licenciatura, Universidad de Guayaquil, Guayaquil, Guayas, Ecuador. 46 p. http://repositorio.ug.edu.ec/handle/ redug/ 1678

Smith M. T., \& J.T. Addison. 2003. Methods for stock assessment of crustacean fisheries. Fisheries Research 65: 231-256. https:// doi.org/10.1016/j.fishres.2003.09.017

Solano F. 2011. Análisis de las capturas del cangrejo rojo (Ucides occidentalis) en puertos de las provincias del Guayas y El Oro en Ecuador, durante el 2010. Boletín Científico y Técnico (Instituto Nacional de Pesca, Ecuador) 21(3): 1-9.

Solano F., L. Flores \& W. Ruiz. 2010. Capturas de Cangrejo Rojo durante el 2009 en los Puertos de la Provincia de Guayas y El Oro, Ecuador. Boletín Científico y Técnico (Instituto Nacional de Pesca, Ecuador) 20(8): 1-15. http://hdl.handle. net $/ 1834 / 4793$

Solano F., \& J. Moreno. 2009. Cangrejo rojo (Ucides occidentalis) un análisis durante el período de veda reproductiva, 2009. Boletín Científico y Técnico (Instituto Nacional de Pesca, Ecuador) 20(3): 37-45. http://hdl.handle.net/1834/4564

Solano F., W. Ruiz, T. Villegas \& L. Flores. 2012. La pesquería del cangrejo rojo (Ucides occidentalis) en puertos de la Provincia de El Oro en Ecuador en el 2011. Boletín Científico y Técnico (Instituto Nacional de Pesca, Ecuador) 22(3): 17-27.

Števčić Z. 2005. The reclassification of Brachyuran crabs (Crustacea: Decapoda: Brachyura). Natura Croatica 14(1): 1-159.

Tazan G., \& B. Wolf. 2000. Estudio Bioecológico, in: El cangrejo rojo Ucides occidentalis (Ortmann) en la Reserva Ecológica Manglares Churute, pp. 69-117. Guayaquil: CEDEGE, Distrito Forestal del Guayas-Ministerio del Ambiente y Fundación Natura, Guayaquil, Ecuador, p. 69-117.

Twilley R., M. Pozo, V. Garcia, V. Rivera-Monroy, R. Zambrano \& A. Bodero. 1997. Litter dynamics in riverine mangrove forests in the Guayas River estuary, Ecuador. Oecologia 111(1): 109-122. https://doi.org/10.1007/s004420050214

Valverde-Valdés M.T. 1999. Las metapoblaciones en la naturaleza, ¿realidad o fantasía? Ciencias 53: 53-63.

Villegas T. 2012. Variabilidad interanual en la tasa de captura del cangrejo rojo Ucides occidentalis en el estuario del Archipiélago de Jambelí y el Golfo de Guayaquil. Tesis de Licenciatura, Universidad de Guayaquil, Guayaquil, Guayas, Ecuador. 21 p. http://repositorio.ug.edu.ec/handle/redug/4745

Von Bertalanffy L. 1938. A quantitative theory of organic growth (inquiries on growth laws II). Human Biology 10: 181-213.

Wright H.O. 1968. Visual displays in Brachyuran crabs: Field and laboratory studies. American Zoologist 8: 655-665. https:// doi.org/10.1093/icb/8.3.655

Zambrano R. 2014. Capturas comerciales del cangrejo rojo de manglar (Ucides occidentalis) durante el 2012, en el Golfo de Guayaquil, Ecuador. Boletín Especial (Instituto Nacional de Pesca, Ecuador) 5(1): 1-11.

Zambrano R. 2016. Período reproductivo de Ucides occidentalis en el Golfo de Guayaquil, Ecuador. Revista Científica de Ciencias Naturales y Ambientales 10(2): 102-106.

Zambrano R. 2017a. Crecimiento del cangrejo rojo (Ucides occidentalis) en el Golfo de Guayaquil, Ecuador: estimación por métodos indirectos y enfoque multimodelo. Tesis de Maestría, Universidad Veracruzana, Veracruz, México. 53 p.

Zambrano R. 2017b. First record of malformations in males of Ucides occidentalis (Brachyura, Ocypodidae) in the Gulf of Guayaquil, Ecuador. Crustaceana 90(5): 631-638. https://doi. org/10.1163/15685403-00003678

Zambrano R., \& E.A. Aragón-Noriega. 2016. Sexual dimorphism and morphometric maturity in males of Ucides occidentalis (Ortmann, 1897) (Brachyura, Ocypodidae) in the Gulf of Guayaquil, Ecuador. Crustaceana 89(10): 1115-1124. https://doi.org/10.1163/15685403-00003582

Zambrano R., E.A. Aragón-Noriega, G. Galindo-Cortes, L. JiménezBadillo \& M. Peralta. 2016. Individual growth estimation of 
Ucides occidentalis (Brachyura, Ocypodidae) in the Gulf of Guayaquil, Ecuador by indirect methods and multi-model selection. Crustaceana 89(13): 1509-1524. https://doi. org/10.1163/15685403-00003589

Zambrano R., \& F. Solano. 2014. Análisis de las capturas de cangrejo rojo de manglar (Ucides occidentalis), en el Golfo de Guayaquil-Ecuador durante el 2013. Boletín Especial (Instituto Nacional de Pesca, Ecuador) 5(1): 65-73.

Zambrano R. G. Galindo-Cortes \& E.A. Aragón-Noriega. 2018. Comparison of growth pattern of male Ucides occidentalis (Ortmann, 1897) (Brachyura: Ocypodidae) based on a combination of commercial catches and non-commercial data, Journal of Crustacean Biology 38(2): 6 pp. https:// doi.org/10.1093/jcbiol/rux105 